\title{
Production of Bio-inseticide Bacillus thuringiensis var. israelensis in Semicontinuous Processes Combined with Batch Processes for Sporulation
}

\author{
Millena da Silva ${ }^{1}$, Agenor Furigo Junior ${ }^{2}$, Sandra Aparecida Furlan ${ }^{1}$ and Ozair Souza ${ }^{*}$ \\ ${ }^{I}$ Departamento de Engenharia Química; Mestrado em Engenharia de Processo; Universidade da Região de \\ Joinville; C.P.: 246; 89.201-972; Joinville - SC - Brasil. ${ }^{2}$ Departamento de Engenharia Química; Universidade \\ Federal de Santa Catarina; C.P.: 476; 88040-900; Florianópolis - SC - Brasil
}

\begin{abstract}
The aim of this work was to study the production of the bioinsecticide using the aerobic cultivation. Two-stage cultivation process was used: aerobic vegetative growth and end-phase of sporulation (with aeration and without aeration). The cuts of working volume evaluated were 20, 40, 60 and $80 \%$. The highest value of spore concentration $\left(2.17 \times 10^{9} \mathrm{CFU} / \mathrm{mL}\right)$ and spore productivity $\left(7.2 \times 10^{7} \mathrm{CFU} / \mathrm{mL} . \mathrm{h}\right)$ were observed using SP60. The lethal concentration $\left(C_{50}\right)$ obtained through the aeration process and non-aeration process were 0.21 and 0.05 $\mathrm{mg} / \mathrm{L}$, respectively. The specific potential of the bioinsecticide produced without aeration $\left(0.025 \mathrm{mg} / 10^{-12} \mathrm{CFU}\right) \mathrm{was}$ two times higher than that obtained with aeration $\left(0.05 \mathrm{mg} / 10^{-12} \mathrm{CFU}\right)$.
\end{abstract}

Key words: semicontinuous fermentation, combined process, bti, bioinsecticide

\section{INTRODUCTION}

The preparations of spores and crystals of Bacillus thuringiensis have been used for about 60 years for the control of insects harmful to the cultivated plants and forests and, also, for the control of insect vectors of diseases. Until 2002, 14 commercial formulations of $B$. thuringiensis were available in the Brazilian market (Azevedo, Barros and Serafini, 2002). The increase of the demand of the bioproduct in comparison to chemical products is due to many advantages of the bioproduct. Azevedo et al., (2002) mentioned some of these advantages: the production through bioprocesses, use of the same equipments used for the application of chemical insecticides, innocuity to mammals and other vertebrates, and the wide spectrum of action combined with a high specificity. According to Polanczyk (2004), the main limitations of the bioproduct are the competition with the chemical products and the lack of investment of the public and private sectors in the development and formulations of the bioproduct.

Among the main insect vectors of human diseases are the families of Aedes mosquitoes and Simuliidae, responsible for the transmission of a number of diseases. Dengue, in its classic form or hemorrhagic, is one of the diseases transmitted by the mosquito Aedes aegypti, is an important public health problem. Presently, the occurrence area as well as the number of people affected by this

*Author for correspondence: osouza@univille.br 
disease is increasing in parallel with the human concern about its control (Macoris, 2003).

Other mosquitoes that cause damage to the man in southern Brazil are the black flies, especially Simulium pertinax. When not controlled efficiently, the infestation of these insects can provoke a quite uncomfortable life for the riverside populations. The increase of the intensity of its attacks can lead to local hemorrhages, edemas and fever. Furthermore, the presence of those mosquitoes can negatively influence the economic development of the region which has a great potential for the exploration of rural tourism. Local and regional governments have developed programs to combat these insects through periodic applications of commercial products based on Bacillus thuringiensis var. israelensis in order to maintain the level of infestation of the insects in 10 insects/hour/man, in accordance with the recommendation of the World Health Organization (WHO, 1991). The high costs of import and application of those products have hindered the maintenance of the programs.

The toxicity of Bti to flies is due to the crystal delta-endotoxin protein formed during the sporulation of the bacterium when cultivated in controlled processes. These crystals are formed by protoxins that, after the ingestion through the larvae of the insect, are solubilized by the alkaline $\mathrm{pH}$ of its intestine, destroying the walls of the intestine and causing death by starvation or septicemia (Du and Nickerson, 1996). Lacey and Undeen (1986) observed that the lysis of the intestinal cells of the larvae of the mosquito can lead to death within six minutes, when elevated concentrations of the toxin are employed, or within $24 \mathrm{~h}$, in case of low concentrations. Therefore, a reasonable way of elevating the degree of toxicity of these crystals, increasing the concentration of the biotoxin in the product, can be by the development of alternative fermentation processes in comparison to the batch process.

Several papers have been published on batch (BP) and fed-batch Bti fermentation but no information was found about the application of semicontinuous processes (SP). This is the main objective of this work. The production of Bacillus thuringiensis variety israelensis was evaluated in SP process for vegetative growth combined with the batch sporulation. Special attention was given to the potential of the bioinsecticide produced during the bacterial sporulation conducted with aeration and without aeration. The batch BP was used as standard for comparison with the SP process combined.

\section{MATERIAL AND METHODS}

The strain of Bacillus thuringiensis var. israelensis IPS 82, serotype H-14, kindly provided by the University of Caxias do Sul, was used for all the experiments. For the cultivation, the following medium was employed (in $\mathrm{g} / \mathrm{L}$ ): glucose, 20. 0; crushed soybean flour, 40.0; water maceration of

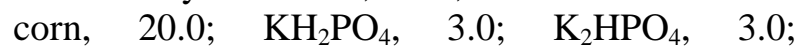
$\mathrm{MgSO}_{4} .7 \mathrm{H}_{2} \mathrm{O}, \quad 0.50 ; \quad \mathrm{CaCl}_{2} .2 \mathrm{H}_{2} \mathrm{O}, \quad 0.40$; $\mathrm{MnSO}_{4} \cdot \mathrm{H}_{2} \mathrm{O}, 0.03$. The sterilization of the medium was conducted at $121^{\circ} \mathrm{C}$ for 20 minutes.

The cultivation was performed by batch process (BP) and semicontinuous combinated process (SP). The inoculum was prepared from microbial suspension the bacteriain grown on the solid medium. Inoculum was used as $10 \%$ of the working volume.

A bioreactor Biostat B (Sartorius) was used with two different configurations. A 2L bioreactor (B1) with working volume of $1.5 \mathrm{~L}$ was used in the experiments BP and SP for bacterial vegetative growth until the application of the cut. A $0.25 \mathrm{~L}$ bioreactor (B2) with a working volume of $0.2 \mathrm{~L}$ was used for the studies of the final phase of sporulation in SP processes. In all the experiments, the temperature was $30^{\circ} \mathrm{C}$ and the $\mathrm{pH}$ remained constant at 7.0 by adding $\mathrm{KOH}(5 \mathrm{M})$. The aeration in $\mathrm{B} 1$ was $0.5 \mathrm{vvm}$ and the agitation rate ranged from 450 to $750 \mathrm{~min}^{-1}$ in order to keep the concentration of dissolved oxygen above $10 \%$ of its concentration of saturation. In B2, the agitation was $600 \mathrm{~min}^{-1}$ with $0.05 \mathrm{vvm}$ in the aerated processes. The total time of cultivation for the SP combined process $(\mathrm{B} 1+\mathrm{B} 2)$ was the same for all the cuts made. The effect of aeration in the final stage of sporulation was also analysed in the SP process.

In the SP, the following cuts of cultivation broth were evaluated: $80 \%$ (SP80), 60\% (SP60), 40\% (SP40) and 20\% (SP20). The cuts are defined as the volume of medium fermented withdrawn from the fermentation bioreactor and replaced by equal volume of fresh medium for new fermentation.

The cuts were performed when the concentration of total reducing sugars (TSR) in the B1 cultivation medium reached $5 \mathrm{~g} / \mathrm{L}$. The removed volume was then transferred to the bioreactor B2 where the influence of aeration on the potential of 
the bioinsecticide was evaluated: sporulation with and without aeration. All the experiments were performed at least in duplicate. The effect of aeration in the stage of maturity on the final concentration of spores $\left(\mathrm{X}_{\mathrm{S}, \mathrm{F}}\right)$ was measured by comparing the results observed for the experiments conducted in bioreactor B2. To achieve that goal, the values of $X_{S, F}$ with and without continuous supply of air to the medium removed were determined. For all the experiments the end of the stage of maturity corresponded to the total consumption of the carbon source available in the cultivation medium. Figure 1 shows the scheme of experiments for the production of spores of Bacillus thuringiensis var. israelensis in the semicontinuous cultivation with subsequent maturing of spores in a batch process.

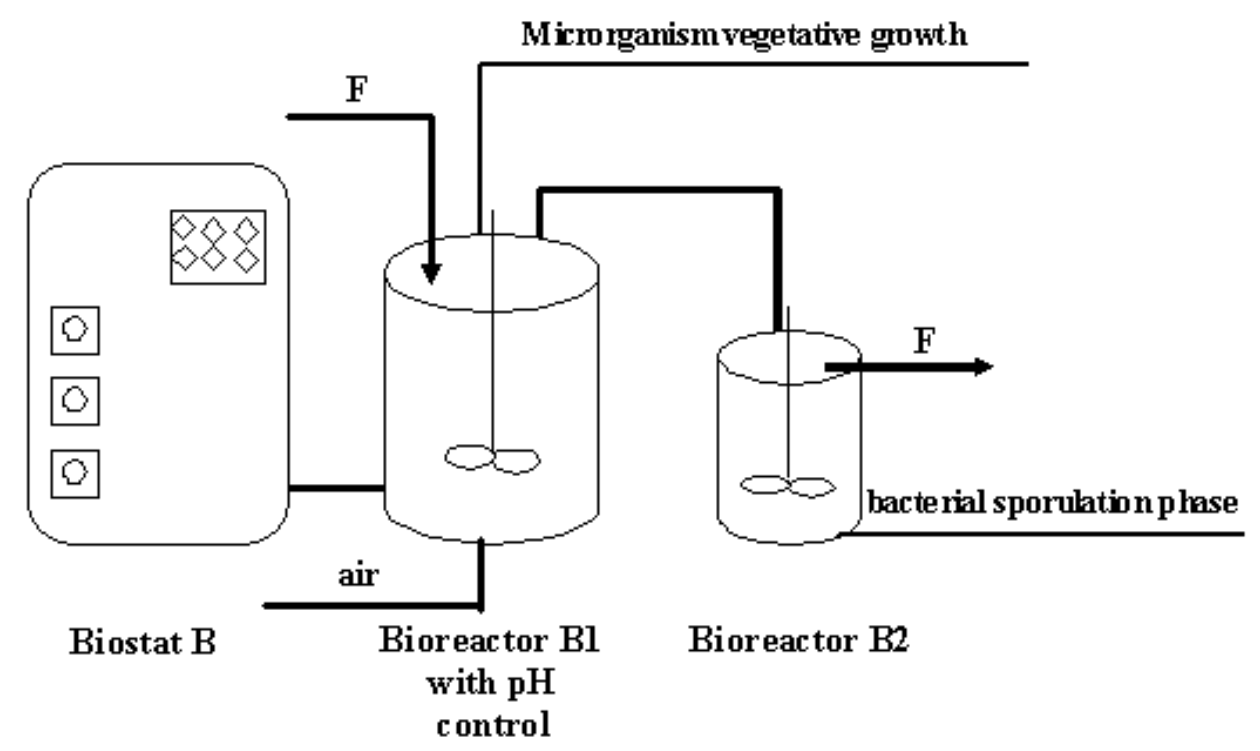

Figure 1- Scheme of the production of spores in the semicontinuous combined process (SP).

During the cultivation carried out in the bioreactor B1, samples $(2 \mathrm{~mL})$ were taken from the culture medium to determine TSR every two hours. For the cell determination (spores), samples were taken before each cut. For the determination of TSR, the samples were centrifuged at $18000 \mathrm{~g}$ for $10 \mathrm{~min}$ and the supernatant was analysed by the DNS method (Miller, 1959). For the determination of the cell concentration (spores), the samples were firstly treated by a thermal shock $\left(80^{\circ} \mathrm{C}\right.$, $\left.10 \mathrm{~min} /-20^{\circ} \mathrm{C}, 10 \mathrm{~min}\right)$, in order to guarantee that only spores were present in the sample. A fraction of this sample was then diluted in a series of sterilized test tubes of $25 \mathrm{~mL}$, containing a $0.9 \%$ $(\mathrm{m} / \mathrm{vol})$ saline solution. Fractions of $100 \mu \mathrm{L}$ of these dilution series were distributed in Petri dishes with subsequent addition of the cultivation medium of Nutritious Agar (Merck), following the Pour-plate method. The inoculated Petri dishes were incubated at $30^{\circ} \mathrm{C}$ for $24 \mathrm{~h}$. Colonies were counted after 12 and $24 \mathrm{~h}$ incubation. The values of viable spore concentrations were expressed in colony forming, units per milliliter of sample (CFU/mL).

The larvicidal activity of the products obtained during the cultivation process were done through bioassays using larvae of 4th initial ínstar of the mosquito Aedes albopictus, according to the method proposed by Draft (1999).

\section{RESULTS AND DISCUSSION}

Figure 2 shows the results for the production of the bioinsecticide Bti in BP.

The profile of the curves (Figure 2) was typical for this type of cultivation and similar to that observed by Passos (2000) who used the same microorganism and a similar cultivation medium. However, the final concentration of spores 
observed in the $\mathrm{BP}$ process described here $\left(5.8 \pm 0.3 \times 10^{7} \mathrm{CFU} / \mathrm{mL}\right)$ was two times higher than that obtained by Passos $\left(2.7 \times 10^{7} \mathrm{CFU} / \mathrm{mL}\right)$. In a previous work, Berbert-Molina (1998) employing a synthetic cultivation medium composed of glucose, yeast extract, and inorganic salts had obtained a final concentration of spores up to 1.2 $\mathrm{x} 10^{6} \mathrm{CFU} / \mathrm{mL}$. The value was 48.3 times lower than that obtained in the present work.

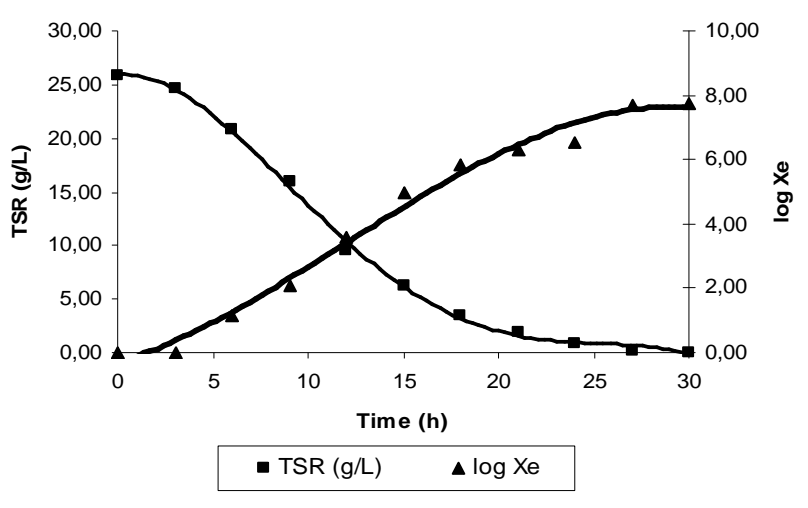

Figure 2 - Concentration of TSR $(\mathrm{g} / \mathrm{L})$ and logarithm of the concentration of spores $(\log \mathrm{Xe})$ against time in the process of growing batch BP.

The positive effect of the complex medium (using bioproducts like soybean) for the cultivation of Bacillus was also observed by other authors (Montiel, 2001; Vidyarthi et al 2002). Montiel (2001) used $15 \mathrm{~g} / \mathrm{L}$ of soy bean flour and $5 \mathrm{~g} / \mathrm{L}$ of glucose and obtained $5.1 \times 10^{8} \mathrm{CFU} / \mathrm{mL}$ while Vidyarthi et al (2002), using a cultivation medium of hydrolyzed sludge from a sewage treatment plant obtained $1.8 \times 10^{7} \mathrm{CFU} / \mathrm{mL}$.

Besides the effect of the composition of culture medium on the final concentration of spores, another strategy would change it to the type of process employed. Replacing the BP otherwise driving (fed-batch, or continuous secontinuous) usually has a higher cell concentration with higher productivity. Amin et al. (2008), develop a costeffective process for bioinsecticide production by B. thuringiensis. The process was designed as a two-stage process; a first stage of active growth, where glucose and other nutrients were adequately supplied to the growing cells over $12 \mathrm{~h}$, followed by a second stage of $2 \mathrm{~h}$ for spore formation and toxin release. The authors obtained a high spore concentration of $2.31 \times 10^{12} \mathrm{CFU} / \mathrm{ml}$ and a lowest $\mathrm{LC}_{50}(40.1$ and $50.2 \mathrm{mg} / \mathrm{L})$ against Egyptian cotton leafworm and Spodoptera littoralis, respectively.
No information was found about the application of semicontinuous technique for the production of $B$. thuringiensis, which was the main purpose of the present work.

Figure 3 shows the values of the spores concentration obtained through the four cuts performed in the SP process and in the BP process. According to Figure 3, the experiment SP60 showed the highest final concentration of spores $\left(\mathrm{Xef}=2.17 \times 10^{9} \mathrm{CFU} / \mathrm{mL}\right)$ and consequently, the highest productivity $\left(7.2 \times 10^{7}\right.$ CFU/mL.h). The value of Xef obtained under this conditions was $36 \%$ higher than that obtained for SP40 $\left(1.43 \times 10^{9}\right.$ $\mathrm{CFU} / \mathrm{mL}), 34 \%$ higher than that of SP20 $\left(1.39 \times 10^{9}\right.$ $\mathrm{CFU} / \mathrm{mL}$ ) and $94 \%$ higher than that of SP80 $\left(1.24 \times 10^{8} \mathrm{CFU} / \mathrm{mL}\right)$. The discrepancy observed between the values of the SP60 and SP80 was expected due to the large cutting volume. The results of the experiment SP80 was close to those achieved in the batch experiment, which also showed a much lower concentration of spores compared to the other experiments. Compared to the batch process (BP), SP60 enabled an increase of $97 \%$ in the final concentration of spores. No values were found in literature for Bacillus thuringiensis in semicontinuous process. 


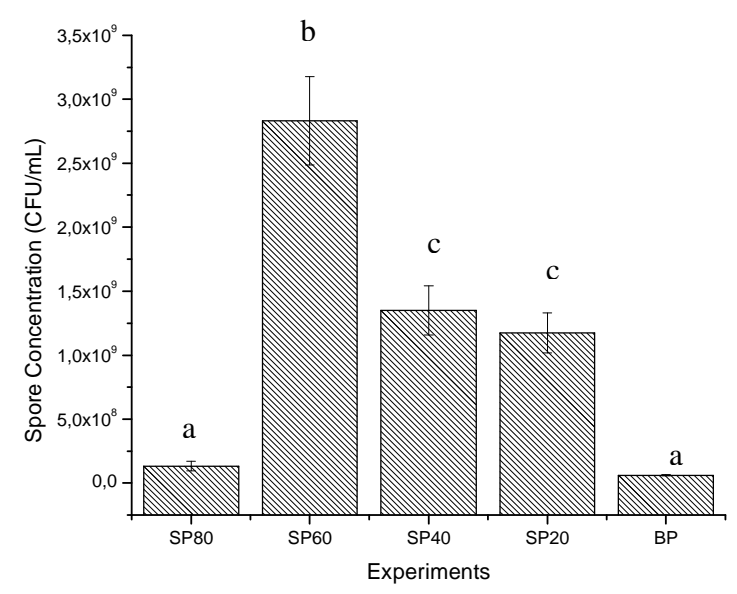

Figure 3 - Average concentrations of spores $\mathrm{Xe}(\mathrm{CFU} / \mathrm{mL})$ observed at the end of the period of maturation (bioreactor B2) from cuts made in bioreactor B1 from 80 to $20 \%$ of the work volume (SP80, SP60, SP40, SP20). The test BP presents the final concentration of spores in the batch process. The averages do not differ significantly among themselves for the test of Tukey in level of $5 \%(\mathrm{p}<0.05)$

Other types of production processes alternative to batch processes were evaluated by Kang et al., (1992) and by Mignone and Rossa (1993). Kang et al., (1992) employed a fed-batch process combined with a batch process during the stage of maturation of the spores with a maximum concentration of the spores $\left(1.1 \times 10^{9} \mathrm{CFU} / \mathrm{mL}\right)$. The authors highlighted the importance of the batch process during the final stage for the production and maturation of the spores. But they did not determine the productivity and not even the values of toxicity of the products. Mignone and
Rossa (1993), using a fed-batch process, obtained a maximum concentration of $5.3 \times 10^{8} \mathrm{CFU} / \mathrm{mL}$ and reported a lower toxicity when this process was used in comparison to the batch process. However, toxicity values were not presented. The experiment SP60 was selected for further studies about the influence of dissolved oxygen on the potential of the produced bioinsecticides. Figure 4 shows the productivity observed in the cultures with and without aeration (bioreactor B2; Figure 1).

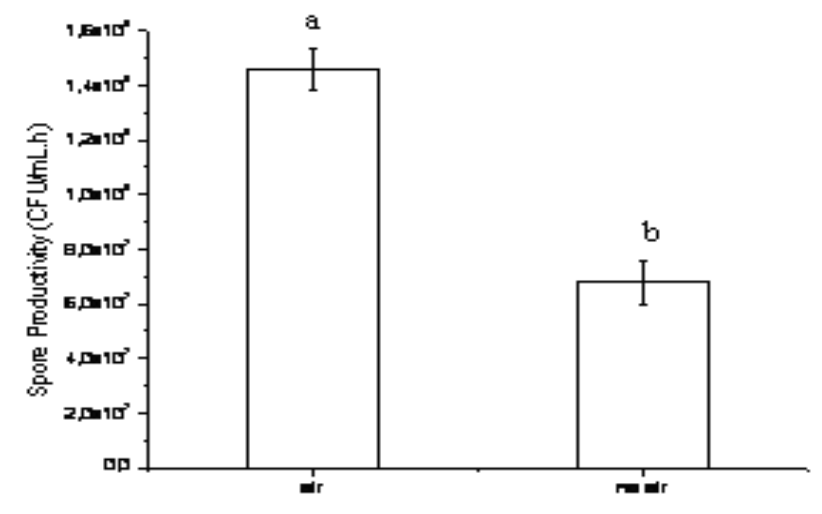

Figure 4- Productivity of spores (CFU/mL.h) at the end of the sporulation phase in the experiment SP60, with aeration (A) and without aeration (B). Averages of the same letters do not differ significantly among themselves for the test of Tukey at the level of $5 \%(\mathrm{p}<0.05)$ 
As shown in Figure 4, air supply was a very important factor in the production of spores in bioreactor $\mathrm{B} 2$, resulting in a $53.6 \%$ increase in sporulation, when compared to the experiment without aeration. Despite the highest productivity under aerated conditions, the toxicity was about four times higher under non-aerated conditions. In bioassays, the final product obtained under aeration presented a lethal concentration $\left(\mathrm{LC}_{50}\right)$ of $0.21 \mathrm{mg} / \mathrm{L}$, while under non-aerated conditions, it was $0.05 \mathrm{mg} / \mathrm{L}$. These results are important for the commercial production where the production of biomass is associated with toxicity and costs. Table 1 shows the $\mathrm{LC}_{50}$ of batch processes (BP), semicontinuous process (SP60), commercial product Vectobac AS and the values found by other authors: Maldonado-Blanco et al (2003) in continuous culture and Prabakaran et al (2007) in fed-batch culture.

Table $1-\mathrm{LC}_{50}$ values of bioinsecticides obtained in batch process (BP), semi-continuous liquid culture (SP60), taking the commercial products Vectobac AS and others works.

\begin{tabular}{cccccc}
\hline & $\mathrm{BP}$ & $\mathrm{SP} 60$ & Vectobac AS & \multicolumn{2}{l}{ Others works } \\
\cline { 2 - 6 } $\mathrm{LC}_{50}(\mathrm{mg} / \mathrm{L})$ & 0.83 & 0.21 & 0.019 & $0.2675^{*}$ & $14.02 * *$ \\
\hline
\end{tabular}

* Maldonado-Blanco et al. (2003), ** Prabakaran et al. (2007)

Table 1 showed that the SP60 product concentration necessary to kill $50 \%$ of the target insect larvae within $24 \mathrm{~h}$ after its application was $0.21 \mathrm{mg} / \mathrm{L}$. This value presented greater degree of toxicity against mosquito larvae when compared to the other bioinsecticides, except to Vectobac AS. In accordance with the values of $\mathrm{LC}_{50}$ obtained it was possible to notice that the specific potential of the bioinsecticide produced without aeration $\left(0.025 \mathrm{mg} / 10^{12} \mathrm{CFU}\right)$ was two times higher than that obtained with aeration $\left(0.05 \mathrm{mg} / 10^{12} \mathrm{CFU}\right)$.

The positive effect of the aeration on the final concentration of spores was supposed by Mignone and Rossa (1993). The authors conducted growth, sporulation and production of the delta-endotoxin by $B$. thuringiensis var. israelensis under the conditions of limitation and non-limitation of oxygen and concluded that the aeration was important to achieve high cell concentrations and high sporulation rates. The final concentration of spores obtained was $9.1 \times 10^{8} \mathrm{CFU} / \mathrm{mL}$ in the aerated process and $4.5 \times 10^{8} \mathrm{CFU} / \mathrm{mL}$ in the cultures with oxygen limitation. Regarding the production of delta-endotoxin, the authors concluded that under the conditions of oxygen limitation, the production was around 50\% lower than the maximum productivity obtained under non-limiting conditions. This behavior in the production of the delta-endotoxin did not agree with the result obtained in this work.

Maldonado-Blanco et al. (2003), analysed $B$. thuringiensis israelensis 225 with regard to the influence of the oxygen flow combined with the frequency of agitation on the productivity and toxicity of Bti. The authors obtained better results when a combination of air flow and high agitation was applied because this did not allow the concentration of dissolved oxygen to fall below $26 \%$, thereby not harming the production. Increased productivity and a lethal concentration $\left(\mathrm{LC}_{50}\right)$ of $0.2675 \mathrm{mg} / \mathrm{L}$ were achieved under nonlimitating oxygen conditions. According to the authors high concentrations of cells or spores did not guarantee high concentrations of toxin. Therefore, the determination of the biological activity should be the principal parameter to optimize the production of the bioinsecticide.

Sarrafzadeh and Navarro (2005) observed the highest concentration of spores being $100 \%$ mature under anaerobic conditions for Bacillus thuringiensis H14. But no larvicidal activity against Culex pipiens was reported. In the aerated process less mature spores were produced, but high toxicity was obtained against $C$. pipiens which showed that the formation of the spores and production of biotoxin occurred under different conditions.

Together with the supply of oxygen, other factors also influence the production of biotoxin, such as the source of carbon and nitrogen, the carbonnitrogen ratio, the $\mathrm{pH}$ and the temperature. It is important to understand the correlation of gene expression of the biotoxin, the physiology of the microorganism and the cultivation parameters to obtain high concentrations of toxin. 


\section{CONCLUSIONS}

The experiments performed in semicontinuous combined process presented higher production of spores than those carried out in batch process. Among those, the experiment conducted with cutting volume of $60 \%$ showed the highest concentrations for spores $\left(2.17 \times 10^{9} \mathrm{CFU} / \mathrm{mL}\right)$ and productivity $\left(7.2 \times 10^{7} \mathrm{CFU} / \mathrm{mL} . \mathrm{h}\right)$. These values were $98 \%$ higher than those obtained in the batch process. The oxygen supply showed to be essential for growth and sporulation of B. thuringiensis var. israelensis in submerged cultivation. That was not observed with regard to the toxicity of the product. The $\mathrm{LC}_{50}$ for the experiments conducted with aeration was $0.21 \mathrm{mg} / \mathrm{L}$, while in the case of the non aerated process this value was $0.05 \mathrm{mg} / \mathrm{L}$. The specific capability of the bioinsecticide produced without aeration $\left(0.025 \mathrm{mg} / 10^{-12} \mathrm{CFU}\right)$ was two times higher than that achieved with aeration $(0.05$ $\left.\mathrm{mg} / 10^{12} \mathrm{CFU}\right)$.

\section{REFERENCES}

Amin, G., Alotaibi, S., Narmen, Y. A., Saleh, W. D. (2008) Bioinsecticide production by the bacterium Bacillus thuringiensis. 1. Pattern of cell growth, toxin production and by-product synthesis. Arch. Agron. Soil Sci., 54 (4), 387-394.

Amin, G., Alotaibi, S., Youssef, N. A., Saleh, W.D. (2008) Optimization of a fermentation process for bioinsecticide production by Bacillus thuringiensis. World J. Microbiol. Biotechnol., 24 (11), 2465-2471.

Azevedo, J.L.; Barros, N.M. \& Serafini, L.A., (2002), Biotecnologia: avanços na agricultura $e$ na agroindústria. Caxias do Sul: EDUSC.

Berbert-Molina, M.A., (1998), Estudo da Influencia do Suprimento de Oxigênio e da Concentração de Glicose sobre o Cultivo de Bacillus thuringiensis israelensis IPS82 em Regime Descontínuo. Ph.D. Thesis, Universidade de São Paulo, São Paulo.

Draft. (1999) Determination of the Toxicity of Bacillus thuringiensis subsp. israelensis and B. sphaericus products, 29-33. In: WHO/CDS/CPC/WHOPES/99.2 Guideline specifications for bacterial larvicides for public health use. pp 33.

Du, C.; Nickerson, K.W (1996). Bacillus thuringiensis HD-73 spores have surface localized Cry1Ac toxins: physiological and pathogenics consequences. Appl. Environ. Microbiol., 10, 3722-3726.
Kang, B.C.; Lee, S.Y. Chang, H.N., (1992). Enhanced spore production of Bacillus thuringiensis by fedbatch culture. Biot. L., 14 (8), 721-726.

Lacey, L.A. Undeen, A. H., (1986), Microbial Control of Black Flies and Mosquitoes. Annu. Rev. Entomol., 31, 265-296.

Macoris, M.L.G., Andrighetti M.T.M., Takaku L., Glasser C.M., Garbeloto V.C., Bracco J.E. Resistance of Aedes aegypti from the state of São Paulo, Brazil, to organophosphates insecticides. Mem Inst Oswaldo Cruz. 2003; 98:703-8.

Maldonado-Blanco, M.G.; Solis-Romero, G.; GalánWong, L.J., (2003). The effect of oxigen tension on the production of Bacillus thuringiensis subs. israelensis toxin active against Aedes aegypti larvae. World J. Microbiol. Biotechnol., 19, 671-74.

Miller, G. L. (1959), Use of dinitrosalicylic acid reagent for determination of reducing sugar. Anal. Chem., 31, 426.

Mignone, C.F.; Rossa, C.A., (1993). A simple method for designing fed-batch cultures with linear gradient feed of nutrients. Process Biochem. England: Elsevier Science Publishers.

Montiel, M.L.T.; Tyagi, R.D.; Valero, J.R., (2001). Wastewater treatment sludge as a raw material for the production of Bacillus thuringiensis based biopesticides. Water Res., 35, 3807-16.

Passos, R.F., (2000), Análise do cultivo descontínuo de Bacillus thuringiensis var. israelensis em meio complexo em diferentes concentrações de glicose. PhD Thesis, Departamento de Microbiologia, Centro de Ciências Biológicas, Universidade Federal de Santa Catarina - UFSC, Santa Catarina.

Polanckzyc, R.A., (2004), Estudos de Bacillus thuringiensis Berliner visando ao controle de Spodoptera frugiperda. PhD Thesis. Escola Superior de Agricultura "Luiz de Queiroz", Universidade de São Paulo, São Paulo.

Prabakaran, G., Balaraman, K, Hoti, S. L., Manonmani, A. M. (2007) A cost-effective medium for the largescale production of Bacillus sphaericus $\mathrm{H} 5 \mathrm{a} 5 \mathrm{~b}$ (VCRC B42) for mosquito control. Biol. Cont., 14 (1), 379-383.

Saar, J.H.; Silveira, M.M.; Passos, R.F.; BerbertMolina, M.; Wuthstrack, G.H.; Jonas, R., (1996), Formulação de um meio de produção de Bacillus thuringiensis var. israelensis utilizando resíduos agroindustriais. In: Anais do V SICONBIOL (Simpósio de Controle Biológico), 203p. 9 -14 july.,Foz do Iguaçu, PR.

Sarrafzadeh, M.H.; Navarro, J.M., (2006). The effect of oxygen on the sporulation, delta-endotoxin synthesis and toxicity of Bacillus thuringiensis $\mathrm{H}-14$. World $J$. Microbiol. Biotechnol., 22, 305-310. 
Setti, S.L.; Mouga, D.M.D.S.; Souza,O., (2006), Espécies de borrachudos (Diptera, Simuliidae) ocorrentes no município de Joinville, Santa Catarina. Caderno de Iniciação à Pesquisa. 8, 146-9.

Vidyarthi, A.S.; Tyagi, R.D.; Valero, J.R.; Surumpalli, R.Y., (2002). Studies on the production of $B$. thuringiensis based biopesticides using wastewater sludge as a raw material. Water Res., 36, 4850-4860.
WORLD HEALTH ORGANIZATION. Pesticide application equipment for vector control. Technical Reporter Series, 791, 58p., 1991.

Received: June 18, 2009; Revised: August 26, 2009; Accepted: April 29, 2010. 